\title{
Body Mass Index and Height in the Friedreich Ataxia Clinical Outcome Measures Study
}

\author{
Maya Patel, BS, Ashley McCormick, DO, Jaclyn Tamaroff, MD, Julia Dunn, Jonathan A. Mitchell, PhD, \\ Kimberly Y. Lin, MD, Jennifer Farmer, MS, Christian Rummey, PhD, Susan L. Perlman, MD, \\ Martin B. Delatycki, MBBS, FRACP, PhD, George R. Wilmot, MD, PhD, Katherine D. Mathews, MD, \\ Grace Yoon, MD, Joseph Hoyle, MD, Manuela Corti, PhD, S.H. Subramony, MD, Theresa Zesiewicz, MD, \\ David Lynch, MD, PhD, and Shana E. McCormack, MD, MTR
}

Neurol Genet 2021;7:e638. doi:10.1212/NXG.0000000000000638

\section{Abstract}

\section{Background and Objectives}

Body mass index (BMI) and height are important indices of health. We tested the association between these outcomes and clinical characteristics in Friedreich ataxia (FRDA), a progressive neuromuscular disorder.

\section{Methods}

Participants $(\mathrm{N}=961)$ were enrolled in a prospective natural history study (Friedreich Ataxia Clinical Outcome Measure Study). Age- and sex-specific BMI and height Z-scores were calculated using CDC 2000 references for participants younger than 18 years. For adults aged 18 years or older, height Z-scores were also calculated, and absolute BMI was reported. Univariate and multivariate linear regression analyses tested the associations between exposures, covariates, and BMI or height measured at the baseline visit. In children, the superimposition by translation and rotation analysis method was used to compare linear growth trajectories between FRDA and a healthy reference cohort, the Bone Mineral Density in Childhood Study (n $=1,535$ used for analysis).

\section{Results}

Median age at the baseline was 20 years (IQR, 13-33 years); 49\% ( $n=475)$ were women. A substantial proportion of children (17\%) were underweight (BMI-Z < fifth percentile), and female sex was associated with lower BMI-Z $(\beta=-0.34, p<0.05)$. In adults, older age was associated with higher BMI $(\beta=0.09, p<0.05)$. Regarding height, in children, older age $(\beta$ $-0.06, p<0.05)$ and worse modified Friedreich Ataxia Rating Scale (mFARS) scores $(\beta=-1.05$ for fourth quartile vs first quartile, $p<0.01$ ) were associated with shorter stature. In girls, the magnitude of the pubertal growth spurt was less, and in boys, the pubertal growth spurt occurred later ( $p<0.001$ for both) than in a healthy reference cohort. In adults, in unadjusted analyses, both earlier age of FRDA symptom onset $(=0.09, p<0.05)$ and longer guanineadenine-adenine repeat length (shorter of the 2 GAA repeats, $\beta=-0.12, p<0.01$ ) were associated with shorter stature. Both adults and children with higher mFARS scores and/or who were nonambulatory were less likely to have height and weight measurements recorded at clinical visits.

\author{
Correspondence \\ Dr. McCormack \\ mccormacks1@chop.edu
}

RELATED ARTICLE

Editorial

Body Mass Index and Height in Friedreich Ataxia: What Do We Know?

Page e637 


\section{Glossary}

BMDCS = Bone Mineral Density in Childhood Study; BMI = body mass index; DM = diabetes mellitus; FACOMS = Friedreich Ataxia Clinical Outcome Measure Study; FRDA = Friedreich ataxia; FXN = frataxin protein; GAA = guanine-adenine-adenine; mFARS = modified Friedreich Ataxia Rating Scale; SITAR = superimposition by translation and rotation .

\section{Discussion}

FRDA affects both weight gain and linear growth. These insights will inform assessments of affected individuals in both research and clinical settings.

Friedreich ataxia (FRDA) is a progressive neurodegenerative disorder affecting both children and adults. Neurologic deficits include ataxia, dysarthria, areflexia, sensory loss, and weakness. ${ }^{1}$ FRDA is also a multisystem disease. Common comorbidities include cardiomyopathy, scoliosis, and diabetes mellitus (DM). ${ }^{2}$ The mean age of symptom onset is between 10 and 15 years, although it can vary widely. For approximately $96 \%$ of affected individuals, FRDA is caused by homozygous expanded guanineadenine-adenine (GAA) repeats in intron 1 of the frataxin protein $(F X N)$ gene. The number of triplet repeats on the shorter allele (GAA1) best predicts the genetic severity of disease, with more repeats associated with greater severity. Expanded alleles decrease FXN expression and reduce levels of FXN. FXN is involved in iron-sulfur cluster formation. As a result, FXN deficiency affects the function of iron-sulfur cluster containing enzymes, including mitochondrial respiratory chain complexes, tricarboxylic acid cycle enzymes, and many others. Decreased FXN thus decreases the cell's ability to produce ATP. ${ }^{3-5}$

Metabolic stress in children with FRDA increases the risk for impaired weight gain and growth. In other mitochondrial disorders, failure to thrive is prevalent, especially in children. ${ }^{6}$ At the same time, mitochondrial disorders cause exercise intolerance $^{7}$ and excess fatigue, ${ }^{8}$ leading to inactivity that increases the risk for weight gain and obesity, especially in affected adults. Understanding the relationship between weight gain, growth, and clinical characteristics of FRDA can inform both clinical care and research investigations. The objective of this study was therefore to test the cross-sectional and longitudinal associations between demographic, genetic, and clinical factors and anthropometric outcomes (height and body mass index $[\mathrm{BMI}]$ ) in FRDA.

\section{Methods}

Participants were 961 individuals from 12 international sites enrolled in a prospective natural history study (Friedreich Ataxia Clinical Outcome Measure Study [FACOMS]). Institutional Review Board approval was obtained, and written consent/ assent was obtained from all participants. Annual visits include clinical assessment for the presence or absence of comorbidities (DM, scoliosis, and cardiomyopathy) and neurologic measures including modified Friedreich Ataxia Rating Scale (mFARS) score and ataxia stage. ${ }^{9}$ Ataxia stage is a general disability scale ranging from 0 to 6 in 0.5 unit increments, with higher scores reflecting diminishing function. An ataxia stage of 5 or greater indicates that individuals are mainly nonambulatory, whereas an ataxia stage of 0 indicates no impairment. All FARS and ataxia staging measurements were made by a certified neurologist. In individuals who are homozygous for expanded GAA repeats in the FXN gene, which is the substantial majority of all individuals with FRDA, the length of the GAA repeat expansion in the least affected allele (GAA1) is an index of genetic disease severity that is associated with clinical features of disease, including the age of FRDA symptom onset and burden of comorbidities. ${ }^{10}$ Age of FRDA symptom onset is itself a commonly reported predictor of disease course. ${ }^{9}$

\section{Anthropometrics}

Anthropometric measures (height and weight) were obtained at annual visits in a subset of participants. Age- and sex-specific $\mathrm{BMI}$, height, and weight $\mathrm{Z}$-scores were calculated using CDC 2000 growth references for participants younger than 18 years. ${ }^{11}$ For adults aged 18 years or older, the reference range for 20 years was used to calculate height $\mathrm{Z}$-scores to permit comparisons across the lifespan because overall height does not change substantially after skeletal maturation, except some loss later in life. For adults aged 18 years or older, absolute values of BMI are reported. Although BMI does vary during adulthood, ${ }^{12}$ age-specific Z-scores are not available.

\section{Univariate and Multivariate Linear Regression Analyses (Baseline Visit)}

We first performed a cross-sectional analysis of baseline anthropometric outcomes (BMI and height) in individuals with available measurements. Univariate analyses were used to investigate the associations between clinical factors, including sex, age at assessment, age at FRDA symptom onset, genetic characteristics (GAA1, GAA repeat length on the least affected allele), comorbidities (DM, scoliosis, and cardiomyopathy), disease severity (mFARS score), and outcomes of interest (BMI and height). For these analyses, participants' mFARS scores (nonlinear) were divided into quartiles for the overall cohort (first quartile: $4 \leq$ mFARS $<34$, second quartile: $34 \leq \mathrm{mFARS}<46$, third quartile: $46 \leq \mathrm{mFARS}<61$, and fourth quartile: $61 \leq \mathrm{mFARS}<91$ ). We next performed multivariate analyses to test for the independence of effects. 
We tested 2 statistical models. Model 1 included clinical factors: sex, age at the time of measurement, and age of FRDA symptom onset (a commonly used clinical predictor of disease severity). Model 2 added comorbidities (DM, scoliosis, and cardiomyopathy) and mFARS score (a commonly used index of current disease severity). Given the known association between BMI and height in children ${ }^{13}$ and adults, ${ }^{14}$ BMI was also included as a covariate in Model 2 when height was an outcome. We tested each statistical model in pediatric and adult cohorts separately to account for age-specific differences related to growth and puberty.

\section{Growth Trajectory Modeling in Children}

To better understand growth in children with FRDA, we used an approach called superimposition by translational and rotation (SITAR), ${ }^{15}$ which permits assessment of key features of variation in growth including "a," size (individuals can be larger or smaller than average), "b," tempo (the timing of the pubertal growth spurt can be earlier or later than average), and "c," velocity (the duration of the adolescent spurt can be more or less rapid than average). By design, SITAR is equipped to handle missing data and distill complex growth curves into these 3 clinically relevant parameters that can be compared between individuals and groups. We compared children in FACOMSCHOP site with healthy children in a reference cohort, the NIH/NICHD Bone Mineral Density in Childhood Study (BMDCS) of similar population ancestry using the SITAR package (version 1.2.0) in R Studio. ${ }^{16}$ Use of BMDCS was permitted by data use agreement between NICHD and CHOP.

\section{Sensitivity Analyses}

Because a substantial proportion of the cohort was missing height and weight measurements at the baseline visit, sensitivity analyses were performed to compare characteristics between participants with and without anthropometric measurements recorded at the baseline visit. Shapiro-Wilk tests were completed to test for normality; measures that were not normally distributed (age at measurement, age at FRDA symptom onset, and mFARS score) were compared using the Mann-Whitney-Wilcoxon signed-rank test. In addition, $\chi^{2}$ tests were used to compare the proportions of children with and without measurements by ambulatory status.

An analysis was performed using R Studio statistical software version 1.4.1103. A 2 sided $p$ value of 0.05 was taken to indicate statistical significance.

\section{Data Availability}

With appropriate regulatory approvals, deidentified FACOMS data can be made available at the request of investigators for the purposes of replicating results.

\section{Results}

\section{Cohort Characteristics}

Participants were 961 individuals from 12 international sites enrolled in a prospective natural history study (FACOMS). 
Table 2 Baseline Cross-sectional Analysis for BMI in Age-Stratified Cohorts, Multivariate Linear Regression Models

\begin{tabular}{|c|c|c|c|c|}
\hline \multirow[b]{3}{*}{ Input variables } & \multicolumn{4}{|l|}{ Cohort } \\
\hline & \multicolumn{2}{|c|}{ Pediatric (<18 y, BMI Z-score) } & \multicolumn{2}{|c|}{ Adult ( $\geq 18 \mathrm{y}, \mathrm{BMI} \mathrm{kg} / \mathrm{m}^{2}$ ) } \\
\hline & Model $1(n=268)$ & Model $2(n=253)$ & Model $1(n=308)$ & Model $2(n=288)$ \\
\hline Female sex (vs male = reference) & $-0.34(-0.63,-0.05)^{*}$ & $-0.40(-0.69,-0.11)^{\star \star}$ & $0.17(-0.91,1.25)$ & $0.34(-0.81,1.48)$ \\
\hline Age at measurement, y & $-0.002(-0.06,0.06)$ & $0.02(-0.04,0.09)$ & $0.09(0.03,0.15)^{\star \star}$ & $0.09(0.01,0.16)^{\star}$ \\
\hline Age of FRDA symptom onset, y & $0.01(-0.04,0.07)$ & $-0.01(-0.08,0.06)$ & $0.02(-0.05,0.09)$ & $0.02(-0.09,0.14)$ \\
\hline \multicolumn{5}{|l|}{ Comorbidities } \\
\hline Diabetes (vs no diabetes = reference) & - & $1.04(-0.34,2.4)$ & - & $1.77(-0.60,4.15)$ \\
\hline Scoliosis (vs no scoliosis = reference) & - & $-0.31(-0.72,0.09)$ & - & $-0.67(-2.04,0.70)$ \\
\hline Cardiomyopathy (vs no cardiomyopathy = reference) & - & $-0.10(-0.42,0.22)$ & - & $0.13(-1.12,1.39)$ \\
\hline \multicolumn{5}{|l|}{ Disease severity (mFARS score, over cohort) } \\
\hline Second quartile (vs first quartile = reference) & - & $0.24(-0.13,0.61)$ & - & $1.53(-0.23,3.30)$ \\
\hline Third quartile (vs first quartile = reference) & - & $-0.05(-0.49,0.38)$ & - & $1.04(-0.86,2.94)$ \\
\hline Fourth quartile (vs first quartile = reference) & - & $-0.38(-1.29,0.52)$ & - & $0.59(-1.57,2.74)$ \\
\hline \multicolumn{5}{|c|}{$\begin{array}{l}\text { Abbreviations: BMI = body mass index; FRDA = Friedreich ataxia; mFARS = modified Friedreich Ataxia Rating Scale. } \\
\text { Multivariate linear regression analyses were used to investigate the associations between input variables, including sex, age at measurement, age of FRDA } \\
\text { symptom onset, clinical comorbidities (diabetes mellitus, scoliosis, and cardiomyopathy), and clinical disease severity (mFARS score), and BMI (Z-score for age } \\
\text { and sex in children, kg/m² in adults) in FRDA. From the overall study cohort, individuals with available anthropometric measures at the baseline visit were } \\
\text { included in this cross-sectional analysis. "N" values indicate the number of participants with the relevant data for each specific model. Model } 1 \text { included } 3 \\
\text { covariates: age at participant's baseline visit, sex, and the age of FRDA symptom onset. In Model } 2 \text {, clinically relevant information gathered from participants' } \\
\text { initial study visit was added. Covariates included having diabetes, scoliosis, and cardiomyopathy as well as a baseline mFARS score. mFARS scores reflect } \\
\text { degree of disease severity, where a higher score reflects worsening severity. Modeling was completed in age-stratified (children, age }<18 \text { years and adult, age } \\
\geq 18 \text { years) cohorts. } \beta \text { coefficients along with the } 95 \% \text { confidence interval (Cl) are reported. Statistical significance is indicated by } p<0.05 ; * \star p<0.01 \text {. }\end{array}$} \\
\hline
\end{tabular}

Enrolled individuals were FACOMS participants homozygous for expanded GAA repeats in the FXN gene, which is the substantial majority of all individuals with FRDA. Heterozygous individuals, such as those with a point mutation and expanded GAA repeats, were excluded from the analyses. As expected, median GAA1 repeat length was longer in pediatric than adult participants (Table 1). Children had a higher burden of both cardiomyopathy ( $64 \%$ vs $41 \%, p<0.001)$ and scoliosis $(83 \%$ vs $71 \%, p<0.001)$ but were less likely to have diabetes $(1.5 \%$ vs $7.0 \%, p<0.001)$. Seventeen percent of the children were underweight $(\mathrm{BMI}<\mathrm{fifth}$ percentile for age and sex), and $8 \%$ were overweight or obese (BMI $\geq 85$ th percentile). In contrast, in adults, $7 \%$ and $33 \%$ of adult participants were underweight $\left(\mathrm{BMI}<18.5 \mathrm{~kg} / \mathrm{m}^{2}\right)$ and overweight or obese $\left(B M I \geq 25 \mathrm{~kg} / \mathrm{m}^{2}\right)$, respectively; differences in proportions between children and adults were statistically significant, $p<0.001$, by $\chi^{2}$ test. In contrast to the differences in BMI status across age groups, we did not detect a difference in height Z-scores between children and adults.

\section{Availability of Measurements, Sensitivity Analysis (Baseline Visit)}

Recorded height and/or weight were absent in approximately a quarter of participants (eTable 1, links.lww.com/NXG/A494). In both children and adults, individuals who had higher mFARS scores (more clinically severe disease) and/or were nonambulatory were less likely to have measurements taken.

\section{BMI at Baseline (Cross-sectional Analysis)}

In multivariate linear regression analyses (Table 2), in children, we found that girls had a lower BMI Z-score as compared to boys. In adults, in both univariate and multivariate analyses, BMI was higher in older participants, and we did not detect sex differences. Also in adults (eTable 1, links.lww.com/NXG/ A494), in univariate analyses, we found that BMI was higher in individuals with later age of FRDA symptom onset and in those with shorter GAA repeat lengths, as well as those without scoliosis. The associations between BMI and age of symptom onset, shorter GAA repeat lengths, and scoliosis status were attenuated in multivariate models (Table 2).

\section{Height at Baseline (Cross-sectional Analysis)}

Regarding height, in both univariate and multivariate models (eTable 1, links.lww.com/NXG/A494, Table 3), older children were shorter relative to population reference values than younger children. In addition, children with mFARS scores in the highest quartile, indicative of the most clinically severe disease, were substantially shorter than children with mFARS scores in the lowest quartile, in both univariate and multivariate models. In adults, in univariate analyses (eTable 1, links.lww.com/NXG/A494), earlier age of FRDA symptom onset and longer GAA repeat length, both of which are predictors of morbidity, ${ }^{10}$ were associated with shorter stature; however, these results were attenuated in multivariate analyses (Table 3 ). In addition, 
Table 3 Baseline Cross-sectional Analysis for Height Z-Score in Age-Stratified Cohorts, Multivariate Linear Regression Models

\begin{tabular}{|c|c|c|c|c|}
\hline \multirow[b]{3}{*}{ Input variables } & \multicolumn{4}{|l|}{ Cohort } \\
\hline & \multicolumn{2}{|l|}{ Pediatric (age < 18 y) } & \multicolumn{2}{|l|}{ Adult (age $\geq 18$ y) } \\
\hline & Model $1(n=275)$ & Model $2(n=253)$ & Model $1(n=436)$ & Model $2(n=288)$ \\
\hline Female sex (vs male = reference) & $-0.08(-0.33,0.18)$ & $-0.07(-0.32,0.18)$ & $-0.07(-0.24,0.11)$ & $-0.11(-0.34,0.13)$ \\
\hline Age at measurement, y & $-0.06(-0.11,-0.01)^{\star}$ & $-0.07(-0.12,-0.01)^{\star}$ & $0.00(-0.01,0.01)$ & $0.01(-0.01,0.02)$ \\
\hline Age of FRDA symptom onset, $y$ & $0.04(-0.01,0.08)$ & $0.01(-0.05,0.07)$ & $0.01(0.00,0.02)$ & $0.01(-0.01,0.03)$ \\
\hline \multicolumn{5}{|l|}{ Comorbidities } \\
\hline Diabetes (vs no diabetes $=$ reference) & - & $0.34(-0.85,1.53)$ & - & $-0.29(-0.77,0.20)$ \\
\hline Scoliosis & - & $0.20(-0.16,0.55)$ & - & $0.08(-0.20,0.36)$ \\
\hline Cardiomyopathy & - & $-0.13(-0.40,0.15)$ & - & $-0.21(-0.47,0.04)$ \\
\hline BMI (Z-score for age $<18 \mathrm{y}, \mathrm{kg} / \mathrm{m}^{2}$ for age $\geq 18 \mathrm{y}$ ) & - & $0.19(0.08,0.30)^{\star \star \star}$ & - & $-0.03(-0.05,-0.001)^{*}$ \\
\hline \multicolumn{5}{|l|}{ Disease severity (FARS score) } \\
\hline Second quartile (vs first quartile = reference) & - & $-0.27(-0.60,0.05)$ & - & $0.06(-0.30,0.42)$ \\
\hline Third quartile (vs first quartile = reference) & - & $-0.23(-0.61,0.14)$ & - & $-0.02(-0.41,0.37)$ \\
\hline Fourth quartile (vs first quartile = reference) & - & $-1.05(-1.83,-0.28)^{\star \star}$ & - & $0.08(-0.36,0.52)$ \\
\hline
\end{tabular}

Abbreviations: FRDA = Friedreich ataxia; mFARS = modified Friedreich Ataxia Rating Scale.

Multivariate linear regression analyses were used to investigate the associations between input variables, including sex, age at measurement, age of FRDA symptom onset, clinical comorbidities (diabetes mellitus, scoliosis, and cardiomyopathy), clinical disease severity (mFARS score), and weight status (BMI Z-score in children and raw value in adults) and the height in FRDA. Those individuals with available anthropometric measures at their baseline visit were included in this cross-sectional analysis. " $\mathrm{N}$ " values indicate the number of participants with the relevant data for each specific model. Model 1 included 3 covariates: age at participant's baseline visit, sex, and age of FRDA symptom onset. In Model 2, clinically relevant information gathered from participants' initial study visit was added. Covariates included having diabetes, scoliosis, and cardiomyopathy, baseline mFARS score, and BMI. mFARS scores reflect degree of disease severity, where a higher score reflects worsening severity. Modeling was completed in age-stratified (children, age $<18$ years and adult, age $\geq 18$ years) cohorts. $\beta$ coefficients along with the $95 \%$ confidence interval $(\mathrm{Cl})$ are reported. Statistical significance is indicated by ${ }^{*} p<0.05 ;{ }^{* \star} p<0.01 ; * \star \star p<0.001$.

children with higher BMI Z-scores were taller, whereas adults with higher BMI were shorter (Table 3).

\section{Longitudinal Growth Trajectories}

Using SITAR modeling (eTable 2, Figures 1 and 2), we found that ultimately, after puberty, on average, girls were slightly shorter and boys were slightly taller than a healthy reference cohort of similar population ancestry $(p<0.001$ for comparisons in both sexes between FRDA and the healthy reference cohort). In addition, for boys with FRDA, the pubertal growth spurt occurred somewhat later (by just more than 1 year, by $<0.001)$ than in the healthy reference cohort. For girls with FRDA, peak height velocity was slower (by $0.2 \mathrm{~cm} / \mathrm{y}, p<0.001$ ) than in the control reference group.

\section{Discussion}

The main objective of this study was to gain insights about FRDA by measuring weight and height in children and adults with FRDA using an observational, longitudinal, natural history cohort. Regarding weight status, recapitulating findings in smaller cohort studies, ${ }^{17}$ we found that children with FRDA were more likely to be underweight (17\%) than adults with FRDA (7\%). One possible explanation is that individuals with younger age of disease onset also tend have longer GAA1 repeat length and more rapid disease progression. ${ }^{18}$ Indeed, as expected, children had both longer GAA1 repeat length and earlier age of symptom onset as compared to adults in this study. In analyses restricted to children, we did not detect an association between GAA1 repeat length, age of symptom onset, or mFARS and BMI. We speculate that there is less meaningful variance in these parameters with FRDA that could lead to more variation in BMI. Essentially, all children have GAA1 lengths greater than 500 repeats, the threshold at which additional increases in GAA1 length do not substantially decrease the level FXN silencing. ${ }^{19}$

We also found that girls had a lower BMI Z-score than boys by $\sim 0.4$ SDs $(p<0.05)$, even accounting for other clinical factors. Although sex differences are not consistently reported in FRDA, at least 1 previous study reported that women with FRDA progress to using mobility aids more quickly than men. ${ }^{20}$ If lower BMI Z-score is related to lower relative amounts of lean muscle mass in women, this could explain a more rapid functional decline. Lower BMI may also be related to smaller cardiac size in girls. Extremely low BMI has also been associated with cardiovascular disease in individuals 
Figure 1 SITAR Modeled Mean Height Trajectories in Females and Males With FRDA and Individuals of a Similar Population Ancestry in a Healthy Reference Cohort

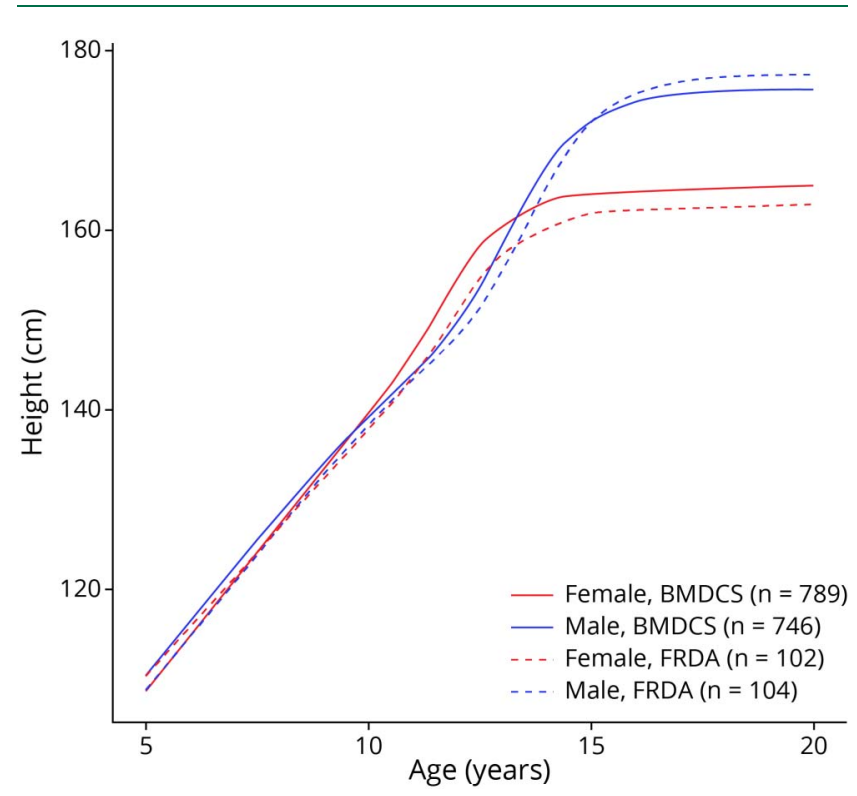

Superimposition by transposition and rotation (SITAR) modeled mean height trajectories (height in cm vs age in years) in females (red) and males (blue) with Friedreich ataxia (FRDA) (dashed lines) as compared to females and males of similar population ancestry in a healthy reference cohort, the Bone Mineral Density in Childhood Study (BMDCS, solid lines). Ultimately, on average, after puberty boys with FRDA ended up taller and girls with FRDA ended up shorter than the reference cohort, both $p<0.001$ for cohortspecific difference in the size ("a" parameter).

without FRDA, possibly related to shared pathogenic factors such as sarcopenia, vitamin/mineral deficiencies, and/or malnutrition, and/or low BMI may be an effect of cardiac disease. ${ }^{21}$ In children with FRDA who had a normal left ventricular ejection fraction, several parameters, including septal wall thickness, left ventricular mass, and left ventricular end-diastolic length, were larger in boys than girls even after accounting for age and body surface area, a different index of size. ${ }^{22}$ Recent studies in FRDA-related cardiac outcomes have emphasized the need to account for age, sex, and size when evaluating left ventricular parameters, ${ }^{22,23}$ and future studies will continue to examine potential effects of sex in more detail.

Very low BMI in children may also capture dimensions of FRDA disease severity that are not reflected by traditional metrics. In other chronic childhood conditions, such as cystic fibrosis, extremely low BMI not only reflects disease status but may also contribute to worse clinical outcomes. ${ }^{24}$ In our pediatric cohort, $64 \%$ had cardiomyopathy, as did $41 \%$ of adults. Cardiomyopathy that is severe and/or rapidly progressive has been associated with longer GAA expansions, ${ }^{25}$ and the difference in cardiomyopathy prevalence in our age-stratified cohorts is likely related to cohort-specific differences in GAA repeat length. In studies of pediatric cardiomyopathy from diverse causes other than FRDA, nutritional status, as reflected by BMI, has been associated with survival outcomes. ${ }^{26}$ In some children with chronic disease, the adverse effects of very low BMI can be mitigated with nutritional interventions. ${ }^{24}$ Although it is plausible that extremely low BMI could lead to worse disease outcomes in children with FRDA, in this observational study with incomplete longitudinal measurements, we were not able to test this.

In children with FRDA, the potential protective benefits of avoiding undernutrition also need to be balanced against the potential risks of excess weight gain in later life. Efforts to avoid the adverse effects of underweight ${ }^{27}$ in childhood could have the undesired effect of contributing to excess weight gain and its adverse effects in adulthood. ${ }^{28}$ In adults with FRDA, we found that older age was associated with higher BMI. One possible cause for excess weight gain with advancing age is that as individuals lose mobility over time, physical activity decreases, leading to excess weight gain. Moreover, excess weight can make physical activity even more challenging, leading to yet more inactivity. Supporting this potential explanation, in adults with other disorders affecting mitochondria, physical activity is inversely associated with BMI. ${ }^{7}$ Fatigue is also commonly reported in individuals with

Figure 2 SITAR Modeled Mean Growth Trajectories in Females and Males With FRDA and Individuals of a Similar Population Ancestry in a Healthy Reference Cohort

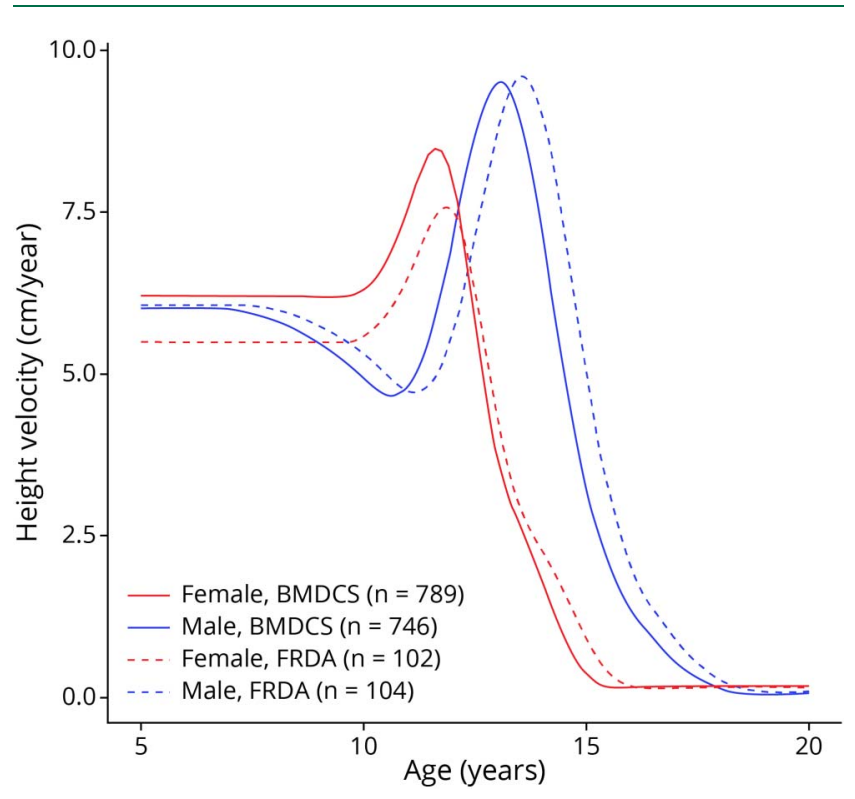

Superimposition by transposition and rotation (SITAR) modeled mean growth trajectories (linear growth in cm/years vs age in years) in females (red) and males (blue) with Friedreich ataxia (FRDA) (dashed lines) as compared to females and males of similar population ancestry in a healthy reference cohort, the Bone Mineral Density in Childhood study (BMDCS, solid lines). Ultimately, on average, boys $(p<0.001)$ had later pubertal timing than the reference cohort, reflected by the cohort-specific difference in the tempo ("b") parameter. Girls had a slower pubertal growth velocity than the reference cohort $(p<0.001)$, reflected by the cohort-specific difference in the velocity ("c" parameter). 
FRDA $^{29,30}$ and could exacerbate inactivity and the associated increase in $\mathrm{BMI}$ over time. In addition, in individuals without FRDA, BMI tends to increase from young adulthood (age 20-39 years) to middle adulthood (ages 40-59 years). ${ }^{12}$ Therefore, the increase in BMI with advancing age in adults with FRDA may also reflect the natural history of BMI during this time of life. Unlike in children, we did not find a significant association between sex and BMI in adults with FRDA. Rising BMI with age in FRDA also has clinical implications. Notably, high visceral adiposity (approximated but incompletely reflected by BMI) has been associated with insulin resistance in adults with FRDA. ${ }^{31}$ Although BMI is associated with DM in individuals without FRDA, previous studies have not demonstrated this association, perhaps related to missing measurements and the limitations of BMI as a reflection of adiposity. ${ }^{32}$ We also did not detect an association between BMI and disease severity in the highest quartile of disease severity in adults. For adults with very severe disease, illness and stress may lead to weight loss and lower BMI, as has been observed in other conditions. ${ }^{33}$ In addition, BMI is only an approximation of body composition $^{34}$ and likely performs less well in very ill populations who may have, for example, significant deficits in lean muscle mass. $^{35}$ In future, more detailed tools to examine body composition in FRDA will help clarify our understanding. For example, waist circumference and/or triceps skinfold measurements are practical assessments that could supplement BMI and give additional information about body composition. $^{37}$

Similar to BMI, height is affected in FRDA in ways that differ between children and adults. In children, we found that height was related to a combination of factors, including age (older children had relatively shorter stature) and clinical disease severity (higher mFARS score was associated with shorter stature). Several possible explanations exist for these observations. First, decreased nutrition, as reflected by low BMI Z-score, can adversely affect linear growth in the setting of chronic illness, as can the stress of the illness itself. Girls, who had lower BMI Z-scores than boys in this cohort, also had overall shorter stature than the healthy reference cohort. In addition, shorter height $\mathrm{Z}$-scores with older age could reflect pubertal differences, and we found decreased pubertal growth in girls and delayed pubertal growth spurt in boys as compared to a healthy reference cohort. Overall shorter stature and decreased pubertal growth in girls may be related to lower BMI, although confirmatory studies would be required to test this possibility. Delays in growth and maturation have been described in other genetic conditions affecting mitochondria. $^{38,39}$ Information regarding pubertal timing (i.e., Tanner staging) is not available in FACOMS but could be obtained in future studies to confirm our observations around puberty. Given previous studies demonstrating that scoliosis leads to a loss of standing height, ${ }^{40}$ we expected that the presence of scoliosis would affect height measurements in both children and adults with FRDA; however, we did not detect an association between scoliosis and height, perhaps because scoliosis is so prevalent in the cohort, and additional clinical details (e.g., the degree of scoliosis and timing of any operative repair relative to the pubertal growth spurt) might be required to discern an effect.

In adults, but not in children, genetic severity of disease (GAA1 repeat length) was associated with shorter stature, analogous to a different study in adults with other genetic mitochondrial disorders that showed height was a biomarker of disease burden. ${ }^{41}$ The authors posited that primary mitochondrial disorders had subtle effects on growth even before clinical diagnosis. Similarly, the bioenergetic changes related to FRDA may antedate more overt symptoms; therefore, even individuals with adult-onset FRDA may have experienced subclinical effects on growth earlier in life. For example, growth plate chondrocytes depend on ATP for hypertrophy and proliferation, and decreased ATP related to impaired mitochondrial oxidative phosphorylation capacity may diminish growth plate expansion. ${ }^{42}$ In addition, there may be peripheral inflammation in $\mathrm{FRDA}^{43}$ that could contribute to suboptimal growth, as has been observed in other conditions. ${ }^{44}$ Finally, we found a negative association between BMI and height in adults, as compared to a positive association between BMI and height in children, recapitulating large, population level epidemiologic patterns that have been observed in individuals without FRDA ${ }^{16,45}$ that may reflect true physiologic associations and/or may be technical artifacts of how BMI normalizes weight for size. Of note, although we detect an effect of sex on height in children, we did not detect this effect in adults.

Missing measurements were a limitation of this study. Measurements were also more likely to be missing in individuals with more clinically severe disease. In addition, there were fewer adults with longer GAA1 repeat lengths, limiting our ability to discern the full impact of the range of disease severity on weight gain and growth throughout the course of the disease. Thus, it will be important to confirm whether this is the case in future studies that include prospective collection of anthropometric measurements across the spectrum of disease severity and across the lifespan. Absence of data in individuals with greater disease severity may be due to inability to complete measurements, which would be important to elucidate to determine alterative measurements to track growth and weight gain in these individuals. Increased attention to collection of anthropometric data and/or utilization of alternative techniques (e.g., recumbent, forearm, or tibial length) in clinical settings could also provide valuable information. In addition, future studies focused specifically on the unique considerations of pediatric participants (e.g., pubertal stage and degree of scoliosis) and adult participants (e.g., loss of height with aging) will help supplemental this study's initial findings.

In summary, we found that growth and weight gain are important indices of health in individuals with FRDA. In children with FRDA, the prevalence of underweight was more 
than 5 times higher and overweight/obesity approximately 2.5 times lower than a similarly aged pediatric U.S. reference cohort. ${ }^{46}$ Over time, individuals with FRDA tended to gain weight, such that by adulthood, the distribution of BMI more closely resembled the general population. Excess weight gain in the general population is associated with an increased risk of cardiometabolic disease, ${ }^{28}$ an insight that has particular relevance for this cohort with increased risk of DM and other complications of weight gain and inactivity. In addition, linear growth, including pubertal timing and velocity, is affected in FRDA. In adults with FRDA, as in adults with other genetic mitochondrial disorders, height was associated with genetic severity of disease, perhaps related to the cumulative effects of the condition.

Taken together, our findings indicate that careful measurements of weight and height in both clinical and research settings have the potential to yield additional relevant insights for health in individuals with FRDA. In particular, studies focused on adolescents could collect pubertal stage in addition to detailed measurements of height and weight to further evaluate pubertal growth patterns. Given that measurements of height and weight were often reported as missing, we propose that alternative measures, such as ulnar length, might be clinically more feasible and still provide valuable insight to an individual's growth and health status. Current preventative guidelines for all individuals recommend making height and weight measurements at health maintenance visits, and this line of investigation will inform the interpretation of these assessments in individuals with FRDA.

\section{Acknowledgment}

This study would not have been possible without the participation of individuals with FRDA in FACOMS and support from clinical and research teams. This work was supported by grants from the Friedreich's Ataxia Research Alliance. The authors acknowledge the BMDCS investigators and NIH/NICHD DASH for use of BMDCS data. The authors acknowledge the BMDCS principal investigators: Vicente Gilsanz, MD, PhD, Heidi Kalkwarf, PhD, Joan Lappe, $\mathrm{PhD}$, Sharon Oberfield, $\mathrm{MD}$, John Shepherd, $\mathrm{PhD}$, and Babette Zemel, PhD. The authors acknowledge NICHD DASH for providing the Bone Mineral Density in Childhood Study data that was used for this research.

\section{Study Funding}

Friedreich's Ataxia Research Alliance.

\section{Disclosure}

The authors report no disclosures relevant to the manuscript. Go to Neurology.org/NG for full disclosures.

\section{Publication History}

Received by Neurology: Genetics June 4, 2021. Accepted in final form August 31, 2021.
Appendix Authors

\begin{tabular}{|c|c|c|}
\hline Name & Location & Contribution \\
\hline $\begin{array}{l}\text { Maya Patel, } \\
\text { BS }\end{array}$ & $\begin{array}{l}\text { Division of Neurology, } \\
\text { Children's Hospital of } \\
\text { Philadelphia; Department of } \\
\text { Neurology, Perelman School } \\
\text { of Medicine at the University } \\
\text { of Pennsylvania, PA }\end{array}$ & $\begin{array}{l}\text { Drafting/revision of the } \\
\text { manuscript for content, } \\
\text { including medical writing } \\
\text { for content, major role in } \\
\text { the acquisition of data, and } \\
\text { analysis or interpretation of } \\
\text { data }\end{array}$ \\
\hline $\begin{array}{l}\text { Ashley } \\
\text { McCormick, } \\
\text { DO }\end{array}$ & $\begin{array}{l}\text { Division of Neurology, } \\
\text { Children's Hospital of } \\
\text { Philadelphia; Department of } \\
\text { Neurology, Perelman School } \\
\text { of Medicine at the University } \\
\text { of Pennsylvania, PA }\end{array}$ & $\begin{array}{l}\text { Drafting/revision of the } \\
\text { manuscript for content, } \\
\text { including medical writing } \\
\text { for content, major role in } \\
\text { the acquisition of data, and } \\
\text { analysis or interpretation of } \\
\text { data }\end{array}$ \\
\hline $\begin{array}{l}\text { Jaclyn } \\
\text { Tamaroff, MD }\end{array}$ & $\begin{array}{l}\text { Division of Neurology, } \\
\text { Children's Hospital of } \\
\text { Philadelphia; Division of } \\
\text { Endocrinology and Diabetes, } \\
\text { Children's Hospital of } \\
\text { Philadelphia, PA }\end{array}$ & $\begin{array}{l}\text { Drafting/revision of the } \\
\text { manuscript for content, } \\
\text { including medical writing for } \\
\text { content, major role in the } \\
\text { acquisition of data, and } \\
\text { analysis or interpretation of } \\
\text { data }\end{array}$ \\
\hline Julia Dunn & $\begin{array}{l}\text { Division of Endocrinology } \\
\text { and Diabetes, Children's } \\
\text { Hospital of Philadelphia, PA }\end{array}$ & $\begin{array}{l}\text { Drafting/revision of the } \\
\text { manuscript for content, } \\
\text { including medical writing for } \\
\text { content, major role in the } \\
\text { acquisition of data, and } \\
\text { analysis or interpretation of } \\
\text { data }\end{array}$ \\
\hline
\end{tabular}

\begin{tabular}{lll}
\hline $\begin{array}{l}\text { Jonathan A. } \\
\text { Mitchell, PhD }\end{array}$ & $\begin{array}{l}\text { Division of } \\
\text { Gastroenterology, } \\
\text { Hepatology and Nutrition, } \\
\text { Children's Hospital of } \\
\text { Philadelphia, PA }\end{array}$ & $\begin{array}{l}\text { Drafting/revision of the } \\
\text { manuscript for content, } \\
\text { including medical writing } \\
\text { for content, and analysis or } \\
\text { interpretation of data }\end{array}$ \\
\hline
\end{tabular}

Kimberly Y. Division of Cardiology, Drafting/revision of the Lin, MD Children's Hospital of manuscript for content, Philadelphia, PA including medical writing for content, and analysis or interpretation of data

\begin{tabular}{|c|c|c|}
\hline $\begin{array}{l}\text { Jennifer } \\
\text { Farmer, MS }\end{array}$ & $\begin{array}{l}\text { Friedreich's Ataxia Research } \\
\text { Alliance }\end{array}$ & $\begin{array}{l}\text { Drafting/revision of the } \\
\text { manuscript for content, } \\
\text { including medical } \\
\text { writing for content, study } \\
\text { concept or design, and } \\
\text { analysis or interpretation } \\
\text { of data }\end{array}$ \\
\hline
\end{tabular}

Christian Clinical Data Science $\mathrm{GmbH}$, Drafting/revision of the Rummey, PhD Basel, Switzerland manuscript for content, including medical writing for content, major role in the acquisition of data, and analysis or interpretation of data

\begin{tabular}{ll}
\hline Susan L. & $\begin{array}{l}\text { Department of Neurology, } \\
\text { Perlman, MD } \\
\text { University of California Los } \\
\text { Angeles }\end{array}$
\end{tabular}

Drafting/revision of the manuscript for content, including medical writing for content, major role in the acquisition of data, and analysis or interpretation of data

\begin{tabular}{|c|c|c|}
\hline $\begin{array}{l}\text { Martin B. } \\
\text { Delatycki, } \\
\text { MBBS, FRCP, } \\
\text { PhD }\end{array}$ & $\begin{array}{l}\text { Murdoch Children's } \\
\text { Research Institute, Victoria, } \\
\text { Australia }\end{array}$ & $\begin{array}{l}\text { Drafting/revision of the } \\
\text { manuscript for content, } \\
\text { including medical writing for } \\
\text { content, major role in the } \\
\text { acquisition of data, and } \\
\text { analysis or interpretation of } \\
\text { data }\end{array}$ \\
\hline
\end{tabular}


Appendix (continued)

\begin{tabular}{|c|c|c|}
\hline Name & Location & Contribution \\
\hline $\begin{array}{l}\text { George R. } \\
\text { Wilmot, MD, } \\
\text { PhD }\end{array}$ & $\begin{array}{l}\text { Department of Neurology, } \\
\text { Emory University School of } \\
\text { Medicine, Atlanta, GA }\end{array}$ & $\begin{array}{l}\text { Drafting/revision of the } \\
\text { manuscript for content, } \\
\text { including medical writing for } \\
\text { content, major role in the } \\
\text { acquisition of data, and } \\
\text { analysis or interpretation of } \\
\text { data }\end{array}$ \\
\hline
\end{tabular}

Katherine D. Department of Pediatrics,

Mathews, MD University of Iowa Carver College of Medicine

Drafting/revision of the manuscript for content, including medical writing for content, major role in the acquisition of data, and analysis or interpretation of data

\begin{tabular}{|c|c|c|}
\hline $\begin{array}{l}\text { Grace Yoon, } \\
\text { MD }\end{array}$ & $\begin{array}{l}\text { Divisions of Neurology and } \\
\text { Clinical and Metabolic } \\
\text { Genetics, Department of } \\
\text { Paediatrics, the Hospital for } \\
\text { Sick Children, University of } \\
\text { Toronto, Ontario, Canada }\end{array}$ & $\begin{array}{l}\text { Drafting/revision of the } \\
\text { manuscript for content, } \\
\text { including medical writing } \\
\text { for content, major role in } \\
\text { the acquisition of data, and } \\
\text { analysis or interpretation of } \\
\text { data }\end{array}$ \\
\hline
\end{tabular}

Joseph Hoyle, Department of Neurology, MD Ohio State University College of Medicine, Columbus

Drafting/revision of the manuscript for content, including medical writing for content, major role in the acquisition of data, study concept or design, and analysis or interpretation of data

\begin{tabular}{ll}
\hline Manuela & Department of Neurology, \\
Corti, PhD & University of Florida, College \\
& of Medicine, Gainesville
\end{tabular}

Drafting/revision of the manuscript for content, including medical writing for content, major role in the acquisition of data, and analysis or interpretation of data

\begin{tabular}{ll}
\hline S.H. & Department of Neurology, \\
Subramony, & University of Florida, College \\
MD & of Medicine, Gainesville
\end{tabular}

Drafting/revision of the manuscript for content, including medical writing for content, major role in the acquisition of data, study concept or design and analysis or interpretation of data

\begin{tabular}{ll}
\hline Theresa & Department of Neurology, \\
Zesiewicz, MD & $\begin{array}{l}\text { University of South Florida, } \\
\text { Tampa }\end{array}$
\end{tabular}

Drafting/revision of the manuscript for content, including medical writing for content, major role in the acquisition of data, study concept or design, and analysis or interpretation of data

\begin{tabular}{lll}
\hline $\begin{array}{l}\text { David Lynch, } \\
\text { MD, PhD }\end{array}$ & $\begin{array}{l}\text { Division of Neurology, } \\
\text { Children's Hospital of } \\
\text { Philadelphia; Department of } \\
\text { Neurology, Perelman School } \\
\text { of Medicine at the University } \\
\text { of Pennsylvania }\end{array}$ & $\begin{array}{l}\text { Drafting/revision of the } \\
\text { manuscript for content, } \\
\text { including medical writing } \\
\text { for content, major role in } \\
\text { the acquisition of data, } \\
\text { study concept or design, } \\
\text { and analysis or } \\
\text { interpretation of data }\end{array}$ \\
\hline $\begin{array}{ll}\text { Shana E. } \\
\text { McCormack, } \\
\text { MD, MTR }\end{array}$ & $\begin{array}{l}\text { Division of Endocrinology } \\
\text { and Diabetes, Children's } \\
\text { Hospital of Philadelphia, PA }\end{array}$ & $\begin{array}{l}\text { Drafting/revision of the } \\
\text { manuscript for content, } \\
\text { including medical writing } \\
\text { for content, major role in } \\
\text { the acquisition of data, } \\
\text { study concept or design, } \\
\text { and analysis or }\end{array}$ \\
& & interpretation of data
\end{tabular}

\section{References}

1. Pandolfo M. Friedreich ataxia. Arch Neurol. 2008;65(10):1296-1303.

2. Delatycki MB, Corben LA. Clinical features of Friedreich ataxia. J Child Neurol. 2012; 27(9):1133-1137.

3. Martelli A, Puccio H. Dysregulation of cellular iron metabolism in Friedreich ataxia: from primary iron-sulfur cluster deficit to mitochondrial iron accumulation. Front Pharmacol. 2014;5:130.

4. Lodi R, Cooper JM, Bradley JL, et al. Deficit of in vivo mitochondrial ATP production in patients with Friedreich ataxia. Proc Natl Acad Sci U S A. 1999;96(20):11492-11495.

5. Bunse M, Bit-Avragim N, Riefflin A, et al. Cardiac energetics correlates to myocardial hypertrophy in Friedreich's ataxia. Ann Neurol. 2003;53(1):121-123.

6. Wolny S, McFarland R, Chinnery P, Cheetham T. Abnormal growth in mitochondrial disease. Acta Paediatr. 2009;98(3):553-554.

7. Apabhai S, Gorman GS, Sutton L, et al. Habitual physical activity in mitochondrial disease. PLoS One. 2011;6(7):e22294.

8. Gorman GS, Elson JL, Newman J, et al. Perceived fatigue is highly prevalent and debilitating in patients with mitochondrial disease. Neuromuscul Disord. 2015;25(7): 563-566.

9. Patel M, Isaacs CJ, Seyer L, et al. Progression of Friedreich ataxia: quantitative characterization over 5 years. Ann Clin Transl Neurol. 2016;3(9):684-694.

10. Durr A, Cossee M, Agid Y, et al. Clinical and genetic abnormalities in patients with Friedreich's ataxia. New Engl J Med. 1996;335(16):1169-1175.

11. Kuczmarski RJ, Ogden CL, Grummer-Strawn LM, et al. CDC growth charts: United States. Adv Data. 2000;314:1-27.

12. Hales CM, Fryar CD, Carroll MD, Freedman DS, Aoki Y, Ogden CL. Differences in obesity prevalence by demographic characteristics and urbanization level among adults in the United States, 2013-2016. JAMA. 2018;319(23):2419-2429.

13. Stovitz SD, Demerath EW, Hannan PJ, Lytle LA, Himes JH. Growing into obesity: patterns of height growth in those who become normal weight, overweight, or obese as young adults. Am J Hum Biol. 2011;23(5):635-641.

14. Diverse Populations Collaborative Group. Weight-height relationships and body mass index: some observations from the Diverse Populations Collaboration. Am J Phys Anthropol. 2005;128(1):220-229.

15. Cole TJ, Donaldson MD, Ben-Shlomo Y. SITAR-a useful instrument for growth curve analysis. Int J Epidemiol. 2010;39(6):1558-1566.

16. McCormack SE, Cousminer DL, Chesi A, et al. Association between linear growth and Bone accrual in a diverse cohort of children and adolescents. JAMA Pediatr. 2017; 171(9):e171769.

17. Greeley NR, Regner S, Willi S, Lynch DR. Cross-sectional analysis of glucose metabolism in Friedreich ataxia. J Neurol Sci. 2014;342(1-2):29-35.

18. Burk K. Friedreich Ataxia: current status and future prospects. Cerebellum Ataxias. 2017;4:4

19. Rodden LN, Chutake YK, Gilliam K, et al. Methylated and unmethylated epialleles support variegated epigenetic silencing in Friedreich ataxia. Hum Mol Genet. 2021; 29(23):3818-3829.

20. Klockgether T, Ludtke R, Kramer B, et al. The natural history of degenerative ataxia: a retrospective study in 466 patients. Brain. 1998;121(pt 4):589-600.

21. Park D, Lee JH, Han S. Underweight: another risk factor for cardiovascular disease?: a cross-sectional 2013 Behavioral Risk Factor Surveillance System (BRFSS) study of 491,773 individuals in the USA. Medicine (Baltimore). 2017; 96(48):e8769.

22. Peverill RE, Romanelli G, Donelan L, Hassam R, Corben LA, Delatycki MB. Left ventricular structural and functional changes in Friedreich ataxia-relationship with body size, sex, age and genetic severity. PLoS One. 2019;14(11):e0225147.

23. Legrand L, Diallo A, Monin ML, et al. Predictors of left ventricular dysfunction in Friedreich's ataxia in a 16-year observational study. Am J Cardiovasc Drugs. 2020; 20(2):209-216.

24. Goss $\mathrm{CH}$, Sykes J, Stanojevic S, et al. Comparison of nutrition and lung function outcomes in patients with cystic fibrosis living in Canada and the United States. Am J Respir Crit Care Med. 2018;197(6):768-775.

25. Bidichandani SI, Delatycki MB. Friedreich Ataxia. 1998 Dec 18 [Updated 2017 Jun 1]. In: Adam MP, Ardinger HH, Pagon RA, et al., editors. GeneReviews ${ }^{\circledast}$ [Internet]. Seattle (WA): University of Washington, Seattle; 1993-2021.

26. Castleberry CD, Jefferies JL, Shi L, et al. No obesity paradox in pediatric patients with dilated cardiomyopathy. JACC Heart Fail. 2018;6(3):222-230.

27. Saunders J, Smith T. Malnutrition: causes and consequences. Clin Med (Lond). 2010; 10(6):624-627.

28. Jensen MD, Ryan DH, Apovian CM, et al. AHA/ACC/TOS guideline for the management of overweight and obesity in adults: a report of the American college of cardiology/American heart association task force on practice guidelines and the obesity society. Circulation. 2014;129(25 suppl 2):S102-S138.

29. da Silva CB, Chevis CF, D'Abreu A, Lopes-Cendes I, Franca MC. Fatigue is frequent and multifactorial in Friedreich's ataxia. Parkinsonism Relat Disord. 2013;19(8): 766-767.

30. Xiong E, Lynch AE, Corben LA, et al. Health related quality of life in Friedreich Ataxia in a large heterogeneous cohort. J Neurol Sci. 2020;410:116642.

31. Cnop M, Igoillo-Esteve M, Rai M, et al. Central role and mechanisms of beta-cell dysfunction and death in friedreich ataxia-associated diabetes. Ann Neurol. 2012; 72(6):971-982.

32. McCormick A, Farmer J, Perlman S, et al. Impact of diabetes in the Friedreich ataxia clinical outcome measures study. Ann Clin Transl Neurol. 2017;4(9):622-631.

33. Aune D, Sen A, Prasad M, et al. BMI and all cause mortality: systematic review and non-linear dose-response meta-analysis of 230 cohort studies with 3.74 million deaths among 30.3 million participants. BMJ. 2016;353:i2156. 
34. Ahima RS, Lazar MA. Physiology. The health risk of obesity-better metrics imperative. Science. 2013;341(6148):856-858.

35. Hou Y, Xie Z, Zhao X, Yuan Y, Dou P, Wang Z. Appendicular skeletal muscle mass: a more sensitive biomarker of disease severity than BMI in adults with mitochondrial diseases. PLoS One. 2019;14(7):e0219628.

36. Bagust A, Walley T. An alternative to body mass index for standardizing body weight for stature. QJM. 2000;93(9):589-596.

37. Silveira EA, Barbosa LS, Rodrigues APS, Noll M, De Oliveira C. Body fat percentage assessment by skinfold equation, bioimpedance and densitometry in older adults. Arch Public Health. 2020;78:65.

38. Al-Gadi IS, Haas RH, Falk MJ, Goldstein A, McCormack SE. Endocrine disorders in primary mitochondrial disease. J Endocr Soc. 2018;2(4):361-373.

39. Chow J, Rahman J, Achermann JC, Dattani MT, Rahman S. Mitochondrial disease and endocrine dysfunction. Nat Rev Endocrinol. 2017;13(2):92-104.

40. Gardner A, Price A, Berryman F, Pynsent P. The use of growth standards and corrective formulae to calculate the height loss caused by idiopathic scoliosis. Scoliosis Spinal Disord. 2016;11:6
41. Boal RL, Ng YS, Pickett SJ, et al. Height as a clinical biomarker of disease burden in adult mitochondrial disease. J Clin Endocrinol Metab. 2019;104(6):2057-2066.

42. Killion CH, Mitchell EH, Duke CG, Serra R. Mechanical loading regulates organization of the actin cytoskeleton and column formation in postnatal growth plate. $\mathrm{Mol}$ Biol Cell. 2017;28(14):1862-1870.

43. Nachun D, Gao F, Isaacs C, et al. Peripheral blood gene expression reveals an inflammatory transcriptomic signature in Friedreich's ataxia patients. Hum Mol Genet. 2018;27(17):2965-2977.

44. Wong SC, Dobie R, Altowati MA, Werther GA, Farquharson C, Ahmed SF. Growth and the growth hormone-insulin like growth factor 1 axis in children with chronic inflammation: current evidence, gaps in knowledge, and future directions. Endocr Rev. 2016;37(1):62-110

45. Sperrin M, Marshall AD, Higgins V, Renehan AG, Buchan IE. Body mass index relates weight to height differently in women and older adults: serial cross-sectional surveys in England (1992-2011). J Public Health (Oxf). 2016;38(3):607-613.

46. Benjamin EJ, Blaha MJ, Chiuve SE, et al. Heart Disease and Stroke Statistics-2017 Update: A Report From the American Heart Association. Circulation. 2017;135(10): e146-e603. 


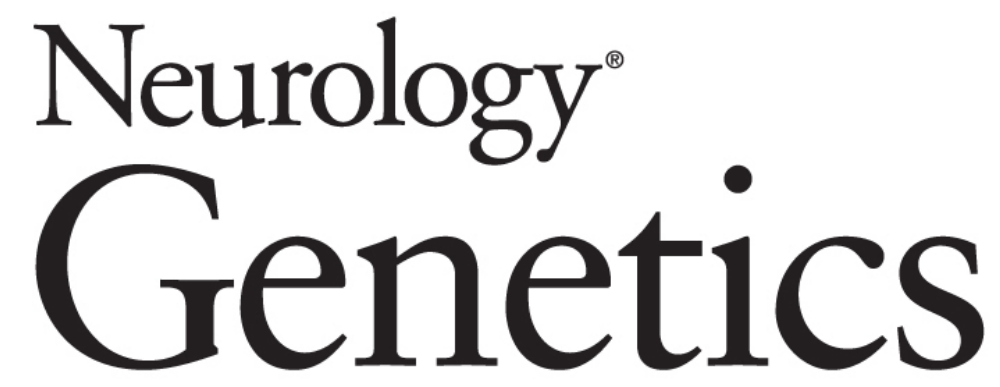
Body Mass Index and Height in the Friedreich Ataxia Clinical Outcome Measures Study
Maya Patel, Ashley McCormick, Jaclyn Tamaroff, et al. Neurol Genet 2021;7;
DOI 10.1212/NXG.0000000000000638

This information is current as of November 12, 2021

Neurol Genet is an official journal of the American Academy of Neurology. Published since April 2015, it is an open-access, online-only, continuous publication journal. Copyright Copyright $\odot 2021$ The Author(s). Published by Wolters Kluwer Health, Inc. on behalf of the American Academy of Neurology.. All rights reserved. Online ISSN: 2376-7839.

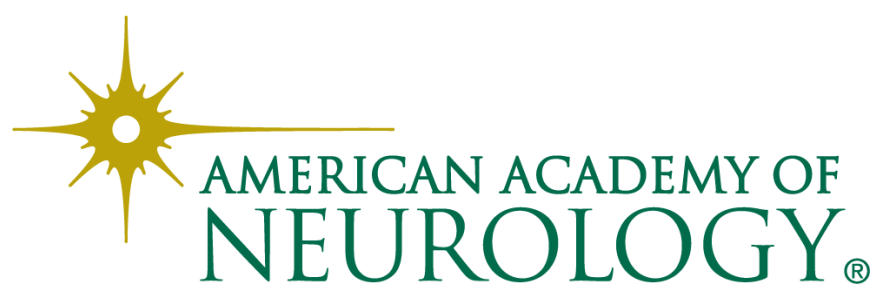




\section{Updated Information \& Services}

References

Citations

Subspecialty Collections

Permissions \& Licensing

Reprints including high resolution figures, can be found at: http://ng.neurology.org/content/7/6/e638.full.html

This article cites 45 articles, 7 of which you can access for free at: http://ng.neurology.org/content/7/6/e638.full.html\#\#ref-list-1

This article has been cited by 1 HighWire-hosted articles: http://ng.neurology.org/content/7/6/e638.full.html\#\#otherarticles

This article, along with others on similar topics, appears in the following collection(s):

Gait disorders/ataxia

http://ng.neurology.org//cgi/collection/gait_disorders_ataxia Mitochondrial disorders

http://ng.neurology.org//cgi/collection/mitochondrial_disorders

Natural history studies (prognosis)

http://ng.neurology.org//cgi/collection/natural_history_studies_prognos is

Trinucleotide repeat diseases

http://ng.neurology.org//cgi/collection/trinucleotide_repeat_diseases

Information about reproducing this article in parts (figures,tables) or in its entirety can be found online at:

http://ng.neurology.org/misc/about.xhtml\#permissions

Information about ordering reprints can be found online:

http://ng.neurology.org/misc/addir.xhtml\#reprintsus

Neurol Genet is an official journal of the American Academy of Neurology. Published since April 2015, it is an open-access, online-only, continuous publication journal. Copyright Copyright ( 2021 The Author(s). Published by Wolters Kluwer Health, Inc. on behalf of the American Academy of Neurology.. All rights reserved. Online ISSN: 2376-7839.

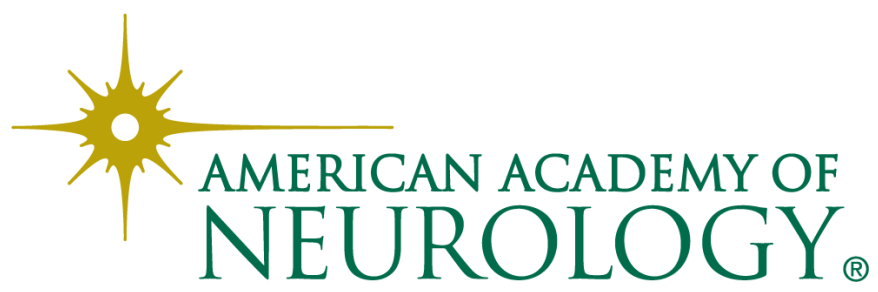

